\title{
A MAP kinase homolog, mpk-1, is involved in ras-mediated induction of vulval cell fates in Caenorhabditis elegans
}

\author{
Mark R. Lackner, ${ }^{1}$ Kerry Kornfeld, ${ }^{2}$ Leilani M. Miller, ${ }^{1}$ H. Robert Horvitz, ${ }^{2}$ and Stuart K. Kim ${ }^{1,3}$ \\ ${ }^{1}$ Department of Developmental Biology, Stanford University Medical Center, Stanford, California 94305 USA; ${ }^{2}$ Howard \\ Hughes Medical Institute, Department of Biology, Massachusetts Institute of Technology, Cambridge, Massachusetts \\ 02139 USA
}

During development of the Caenorhabditis elegans hermaphrodite, the gonadal anchor cell induces nearby Pn.p cells to adopt vulval fates. The response to this signal is mediated by a receptor tyrosine kinase signal transduction pathway that has been remarkably well conserved during metazoan evolution. Because mitogen-activated protein (MAP) kinases are activated by receptor tyrosine kinase pathways in vertebrate cells, we hypothesized that $C$. elegans MAP kinase homologs may play a role in vulval induction. Two $C$. elegans MAP kinase genes, $m p k-1$ and $m p k-2$ (mpk, MAP kinase), were cloned using degenerate oligonucleotide primers and PCR amplification; in parallel, genes involved in vulval induction were identified by screening for mutations that suppress the vulval defects caused by an activated let-60 ras gene. One such suppressor mutation is an allele of $m p k-1$. We used a new type of mosaic analysis to show that mpk-1 acts cell autonomously in the Pn.p cells. Our results show that $m p k-1$ plays an important functional role as an activator in ras-mediated cell signaling in vivo.

[Key Words: Caenorhabditis elegans; mpk-1; MAP kinase; ERK; Ras; vulval development]

Received November 12, 1993; revised version accepted December 8, 1993.

The nematode Caenorhabditis elegans has proven to be an excellent organism for studying cell signaling pathways through genetic analysis (Lambie and Kimble 1991). Some of the best-characterized signaling events in C. elegans occur during the development of the hermaphrodite vulva (Horvitz and Sternberg 1991). The vulva is a passage, formed by specialized ectodermal cells, that connects the gonad to the environment. During vulval development, a signal from the gonadal anchor cell causes three of the six underlying ectodermal cells (P3.p-P8.p, termed Pn.p cells) to adopt vulval fates (Fig. 1) (Kimble 1981). This interaction between the gonadal anchor cell and the Pn.p cells ensures that the vulva is correctly positioned relative to the gonad (Sternberg and Horvitz 1986). The inductive signal from the anchor cell causes the nearest Pn.p cell (P6.p) to generate eight daughter cell nuclei that contribute to the vulva (the $1^{\circ}$ cell fate). The next nearest Pn.p cells (P5.p and P7.p) each generate seven daughter cell nuclei that contribute to the vulva (the $2^{\circ}$ cell fate). The three Pn.p cells located more distantly from the anchor cell (P3.p, P4.p, and P8.p) each generate two daughters that fuse with the

\footnotetext{
${ }^{3}$ Corresponding author.
}

hypodermal syncytium (the nonvulval, $3^{\circ}$ cell fate). Each of these six Pn.p cells can adopt any one of the three potential cell fates $\left(1^{\circ}, 2^{\circ}\right.$, or $\left.3^{\circ}\right)$, and proximity to the anchor cell determines the fate that these cells express (Sternberg and Horvitz 1986; Thomas et al. 1990). Because these cells have equivalent developmental potentials, they are termed the vulval equivalence group. The expression of the $1^{\circ}, 2^{\circ}$, and $3^{\circ}$ cell fates also seems to be controlled by two additional cell signals. A lateral signal either induces expression of the $2^{\circ}$ cell fate or inhibits expression of the $1^{\circ}$ cell fate and thus prevents adjacent Pn.p cells from adopting $1^{\circ}$ cell fates (Sternberg 1988). Also, a signal from the hyp7 hypodermal syncytium inhibits expression of vulval fates by P3.p, P4.p, and P8.p (Herman and Hedgecock 1990).

Genetic and molecular studies have identified $>20$ genes that are required for the proper specification of vulval cell fates (Ferguson et al. 1987; Clark et al. 1992a; Han et al. 1993). Some of these genes are similar to vertebrate genes important for receptor tyrosine kinase-mediated signal transduction pathways. As discussed below, the involvement in vulval signaling of three genes in particular (let-23, let-60, and lin-45) suggested to us that a $C$. elegans mitogen-activated protein (MAP) kinase homolog may act in vulval induction. Partial loss- 


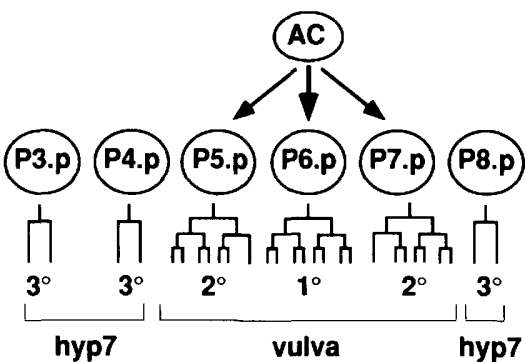

Figure 1. Induction of vulval cell fates in wild-type hermaphrodites (adapted from Sternberg and Horvitz 1986). The gonadal anchor cell $(\mathrm{AC})$ signal induces cells of the vulval equivalence group (P3.p-P8.p) to adopt $1^{\circ}$ or $2^{\circ}$ cell fates; in the absence of the AC signal, Pn.p cells adopt the nonvulval $3^{\circ}$ cell fate. Descendants of cells that adopt $1^{\circ}$ and $2^{\circ}$ cell fates form the vulva, while descendants of cells that adopt $3^{\circ}$ cell fates, contribute to the hyp7 hypodermal syncytium. Lateral and hypodermal signals (Sternberg 1988; Herman and Hedgecock 1990) are not illustrated.

of-function mutations in any one of these three genes cause P5.p, P6.p, and P7.p to adopt nonvulval $3^{\circ}$ fates, indicating that these genes are required for vulval induction by the anchor cell. The let-23 gene has been proposed to encode the receptor for the anchor cell signal, because let-23 encodes a protein that is similar to receptor tyrosine kinases such as epidermal growth factor (EGF) receptor (Aroian et al. 1990). let-60 encodes a protein similar to the GTPase Ras (Han and Sternberg 1990). In mammalian cells, Ras activity can be stimulated by activation of receptor tyrosine kinases (for review, see Barbacid 1987). let-60 ras functions as a switch in the vulval induction pathway (Beitel et al. 1990; Han et al. 1990). let-60 activity is required for vulval induction, because mutations that decrease let-60 activity prevent expression of vulval cell fates. let-60 activity is also sufficient to cause the expression of vulval cell fates; in animals with a mutation that increases let-60 activity, all six Pn.p cells express vulval cell fates. The lin- 45 gene encodes a protein similar to the proto-oncogene Raf (Han et al. 1993), a protein-serine/threonine kinase that binds to activated Ras (Koide et al. 1993; Moodie et al. 1993; Van et al. 1993; Vojtek et al. 1993; Warne et al. 1993; Zhang et al. 1993). Genetic epistasis experiments suggest that let-23 EGFR acts upstream of let-60 ras, whereas lin-45 raf acts downstream of let-60 ras. Specifically, a mutation that results in the constitutive activation of let-60 ras allows Pn.p cells to adopt vulval cell fates independently of let-23 EGFR activity (Han et al. 1990) but not independently of lin-45 raf activity (Han et al. 1993). The conservation of the receptor tyrosine kinase signal transduction pathways in C. elegans and vertebrates suggested to us that other genes known to function in vertebrate tyrosine kinase pathways might function in nematode vulval induction. We decided to focus on MAP kinase genes for several reasons.

First, MAP kinases, also referred to as extracellular signal-regulated kinases (ERKs), act downstream of re- ceptor tyrosine kinases, Ras, and Raf in vertebrate cells (for review, see Pelech and Sanghera 1992). MAP kinases were first identified because they are activated in response to diverse mitogenic signals, many of which are known to act through receptor tyrosine kinases (for review, see Nishida and Gotoh 1993). Subsequently, it was shown that introduction of activated forms of Ras and Raf into mammalian cells causes MAP kinase activation (deVries-Smits et al. 1992; Kyriakis et al. 1992; Thomas et al. 1992; Wood et al. 1992). Furthermore, expression of dominant-negative forms of Ras or Raf-1 blocks MAP kinase activation caused by mitogenic growth factors such as EGF or nerve growth factor (Thomas et al. 1992, Wood et al. 1992; Schaap et al. 1993). The interactions between vertebrate MAP kinases and receptor tyrosine kinases, Ras, and Raf suggest that MAP kinase homologs may interact with let-23, let-60 ras, and lin-45 raf in C. elegans vulval induction.

Second, although some of the steps that lead to the activation of MAP kinases have been established, the functional significance of protein phosphorylation by activated MAP kinases remains unclear. MAP kinases can phosphorylate many different substrate proteins, and the effects of phosphorylation of these various potential targets raise several possibilities, not mutually exclusive, about how MAP kinases may function in signaling pathways. One possibility is that MAP kinases contribute to the mitogenic response. This hypothesis is supported by the observation that MAP kinases phosphorylate and thereby activate the Elk-1 and NF-IL6 transcription factors, leading to the transcriptional activation of two immediate early genes, $c$-fos and the interleukin- 6 gene, respectively (Marais et al. 1993; Nakajima et al. 1993). Furthermore, recent experiments with antisense MAP kinase RNA and putative dominant-negative forms of MAP kinase have shown that inhibition of MAP kinase activity blocks fibroblast proliferation (Pages et al. 1993). A second possibility is that MAP kinases can inhibit the mitogenic signaling response. This hypothesis is supported by the observation that MAP kinases can activate a protein-tyrosine phosphatase, an enzyme that inactivates the EGF receptor tyrosine kinase, leading to the feedback inhibition of the mitogenic signaling pathway (Griswold-Prenner et al. 1993). MAP kinases may also act as feedback inhibitors by directly phosphorylating proteins that act at upstream steps in signal transduction pathways. In vitro, MAP kinases can phosphorylate several such upstream proteins, such as EGF receptor (Northwood et al. 1991; Takishima et al. 1991), Raf (Anderson et al. 1991; Lee et al. 1992), and MEK, a protein kinase that directly activates MAP kinase (Matsuda et al. 1993). However, phosphorylation by MAP kinases has not been shown to affect the activities of these upstream signaling molecules. In addition, MAP kinases may inhibit the activity of downstream targets; MAP kinases can phosphorylate the Jun transcription factor and thereby inhibit its DNA-binding activity (Pulverer et al. 1991; Chou et al. 1992). Thus, MAP kinases may be able to reduce cellular proliferation because activation of $c$-jun function is oncogenic. 
Finally, we focused on MAP kinases because they may be situated at an interesting point in signaling pathways. MAP kinases translocate to the nucleus following activation (Chen et al. 1992; Gonzalez et al. 1993; Lenormand et al. 1993), and they can phosphorylate certain transcription factors in vitro (for review, see Davis 1993). These observations suggest that MAP kinases may link cytoplasmic signaling molecules to changes in transcriptional activity. In addition to being active in the nucleus, MAP kinases are active in other parts of the cell because they can phosphorylate cytoplasmic and membrane-associated proteins.

For these three reasons, it seemed plausible that a MAP kinase gene was involved in the vulval signaling pathway and that a genetic analysis would illuminate its functional role in this pathway. We used degenerate oligonucleotide primers and PCR amplification to clone a C. elegans MAP kinase homolog, mpk-1. Our genetic studies showed that a mutation in mpk-1 suppressed the phenotype caused by a gain-of-function let-60 ras mutation, suggesting that mpk-1 plays an important functional role as a positive transducer of ras-mediated signaling during vulval development. The results from a recently developed method of mosaic analysis showed that mpk-1 acts in Pn.p cells, suggesting a role in the cellular response to the anchor cell signal.

\section{Results}

Isolation and molecular characterization of $\mathrm{C}$. elegans MAP kinase homologs

To identify C. elegans MAP kinase homologs, degenerate oligonucleotide primers corresponding to amino acid sequences conserved in all known MAP kinases were used in polymerase chain reactions (PCR) to amplify sequences from either genomic DNA or cDNA. Amplified fragments were cloned, and sequence analysis revealed that they were derived from two genes. These genes were named mpk-1 and mpk-2, because their sequences exhibited extensive similarity to known MAP kinases. Here, we present a molecular and genetic analysis of mpk-1.

To characterize the structures of the mpk-1 transcripts, both genomic DNA clones and cDNA clones were analyzed. Cloned mpk-1 DNA obtained by PCR amplification (a 940-bp genomic fragment) was used as a probe to isolate a bacteriophage clone containing $18 \mathrm{~kb}$ of DNA from the mpk-1 genomic region $(\lambda \mathrm{mpk}-1)$ (see Materials and methods|. Seven cloned cDNAs were isolated by screening 600,000 plaques from two mixed stage cDNA libraries (Barstead and Waterston 1989), using an mpk-1 genomic DNA fragment as a probe (see Materials and methods). The nucleotide sequences of the longest two cDNAs (contained in pML20 and pML25) were determined; the pML25 cDNA insert was 1858 bp long, and the pML20 cDNA insert extended from nucleotides 96 to 1839 of pML25 (Fig. 2A). In addition, the nucleotide sequence of $4 \mathrm{~kb}$ of genomic DNA from $\lambda$ mpk-1 was determined (see Materials and methods). Figure 2B shows the structure of the $m p k-1$ gene as deduced from the nucleotide sequences of genomic DNA and cDNAs.

A likely poly $(\mathrm{A})^{+}$addition site defining the $3^{\prime}$ end of one class of mpk-1 transcript was suggested by a 15-bp stretch of A residues found at the end of the pML25 insert but not contained in the genomic DNA. None of the cloned cDNAs contained the SLl trans-spliced leader sequence that is frequently found at the $5^{\prime}$ ends of C. elegans transcripts (Krause and Hirsh 1987). To define a $5^{\prime}$ end of mpk-1 transcripts, PCR was used to amplify cDNA derived from mixed stage poly $(\mathrm{A})^{+}$RNA using primers complementary to the SL1 trans-spliced leader sequence and to sequences within mpk-1 exon 6 . Southern blot analysis identified a single $\sim 700$-bp fragment from this reaction that hybridized to mpk-1 DNA. This fragment was cloned, and sequence analysis showed that it contained the 22-nucleotide SL1 leader sequence attached to exon 2 of $m p k-1$. Because the cDNA insert of pML25 contained exon 1 joined to exon 2, these results suggested that alternative splicing yields two forms of mpk-1 transcripts. One form contains exon 1 spliced to exon 2 (1X2), whereas the other form contains SL1 spliced to exon 2 (SLX2). Analysis of RNA blots identified transcripts of 1.9 and $2.1 \mathrm{~kb}$ (Fig. 3A); the sizes of these transcripts suggest that they might correspond to SLX2 and 1X2, respectively. An RNase protection experiment suggested that $\sim 60 \%$ of $m p k-1$ transcripts are form $1 X 2$, whereas $\sim 40 \%$ are form SLX2 (Fig. 3B).

Figure 2A shows the complete coding region of the SLX2 transcript. Our data allow for the possibility that the $1 \times 2$ transcript encodes an amino-terminal extension of the MPK-1 protein. However, the MPK-1 protein encoded by the SLX2 form is functional because genomic DNA that lacks exon 1 and can express only the SLX2 form rescued the mpk-1(n2521) mutant phenotype (described below). Figure 4 shows that the predicted mpk-1 protein encoded by the SLX2 form is $73 \%$ identical to both human ERK1 (273/376 identical residues) and Drosophila melanogaster ERK-A (274/375 identical residues), and $48 \%$ identical to Saccharomyces cerevisiae FUS3 (169/353 identical residues). The protein domains responsible for kinase activity, serine/threonine substrate specificity, and activation by MEK, a MAP kinase activator, are conserved in MPK-1.

\section{Identification of an mpk-1 mutation}

In parallel with the molecular approach that identified MAP kinase homologs, a genetic screen was done to identify genes likely to act downstream of let-60 ras. The allele let-60(n1046gf) encodes an activated mutant protein with a glycine to glutamic acid substitution at position 13 (Beitel et al. 1990). In a population of let-60(gf) mutants, $93 \%$ of the animals exhibit a multivulva (Muv) phenotype (Table 1A). The expression of this Muv phenotype should require the activity of genes that act downstream of let-60 ras. Therefore, it seemed likely that loss-of-function mutations in these downstream genes would suppress the let-60(gf) Muv phenotype. We 
A

TCGAGCAACATACCGAATGGAGCAACCAACCACGTCAGACAACAGAAATGGCAGTACAC

61

121

181

35

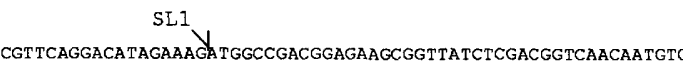

TTCCACTAAGA TTT TGGCATTTCAGTT TCTTT TTCGATGTATCATAATCCACTTCAAAA TCGATCGTTTAGTTGT TAGTAACCCCCCGTTCCCGCTGAAAAGCTTGTTGAAAATTT TC AATATTTTACGTATTTTGTAATATATTCATCCCCCAAAAAATATATATGTATATCCATT CCAGCTGTGATGTGAATGCACCTCCTCCAATTAATCACTCATTAATTATCGATTAGAATT CTGTCAAATTTTTTG TA TAGGAAT TCGCAAAAATCCGCCCATACTTGACTCAATTCCAAT CGGCATTTGAATTTT TTCAAATATTTTTT TCACACACAATTCCATCAGAATCCCGCTGCT AAAATTCCTCTTTTTGAAAAAACCAAAAAATAGTATAATGTTCATCCTATGTGGGATCTC CAATGTTTTTCGTCTCTGTCCACATGTCCTCTTCTCGTTCTCCCTGATTATTCAGTTTTC CAATGTTTTTCGTCTCTGTCCACATGTCCTCTTCTCGTTCTCCCTGATTATTCAGTTTT
B

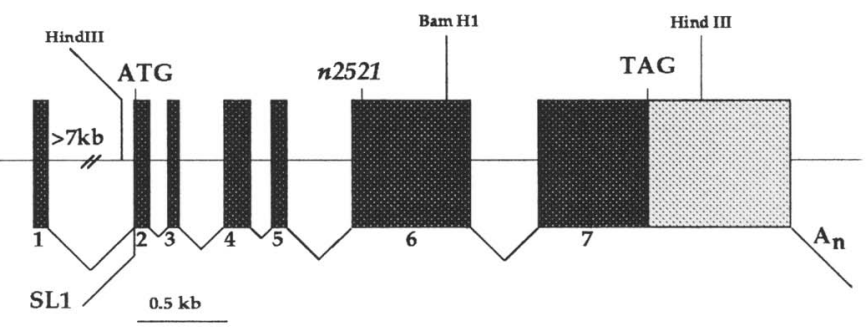

Figure 2. cDNA sequence and exon structure of $m p k-1$. (A) Composite sequence of $m p k-1$ cDNAs. Nucleotide numbers $(t o p)$ begin with the $5^{\prime}$ end of the cDNA insert of pML25. Amino acid numbers (bottom) begin with the putative initiator methionine of the protein encoded by the SLX2 transcript. Vertical lines indicate intron positions; diagonal line indicates the position where a trans-spliced leader (SL1) is spliced to SLX2 transcripts. The leucine altered in n2521 mutants is boxed. $(B)$ Structure of the mpk-1 gene. Exons are numbered and shown as boxes. Introns and untranscribed regions are shown as thin horizontal lines. Splice junctions are indicated as V's between adjacent exons. Solid rectangles indicate the coding region initiated by ATG and terminated by TAG. Stippling indicates the 3 '-untranslated region. $m p k-1$ transcripts contain a poly $(A)^{+} \operatorname{tract}\left(\mathrm{A}_{\mathrm{n}}\right.$ and diagonal line $)$, and SLX2 transcripts contain a trans-spliced leader (SL1 and diagonal line). Exon 1 is not located in the $7-\mathrm{kb}$ region upstream of exon 2 that is present in $\lambda \mathrm{mpk}-1$. The location of the $n 2521$ mutation is indicated. $B a m H I$ and HindIII sites that are present in $\lambda$ mpk-1 are shown. identified 43 independent mutations that reduced the penetrance of the let $-60(\mathrm{gf})$ phenotype so that $<10 \%$ of the animals were Muv (see Materials and methods). These mutations defined 21 complementation groups. The genetic location of one complementation group, consisting of the single allele $n 2521$, is between the unc79 and ced-4 genes on chromosome III /Fig. 5A; Materials and methods); we localized mpk-1 to an overlapping region of chromosome III on the genome physical map (Coulson et al. 1988) by hybridization to an ordered array of genomic DNA cloned in yeast artificial chromosomes (A. Coulson, pers. comm.).

In addition to being colocalized to a small interval of chromosome III, three results showed that the n2521 mutation is in the mpk-1 gene. First, DNA containing the mpk-1(+) gene rescued the n2521 phenotype in germ-line transformation experiments [i.e., n2521; let60(gf); [Exmpk-1(+)] animals, which carry an extrachromsomal array containing copies of the mpk-1(+) gene, were Muv]. Rescuing activity was a consequence of 


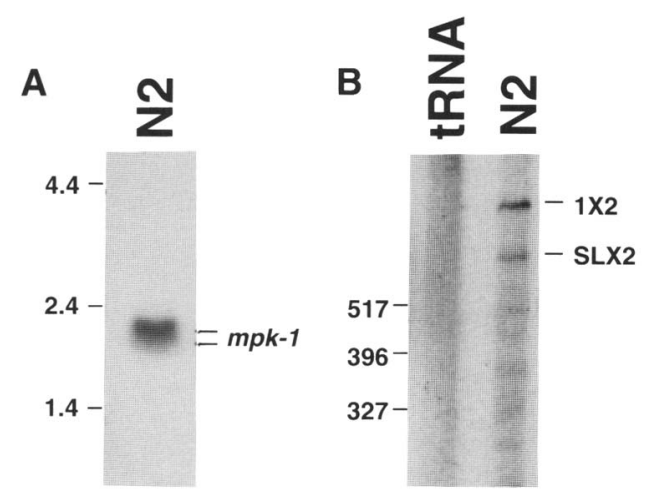

Figure 3. Analysis of $m p k-1$ RNA. (A) Northern blot analysis. Poly $(A)^{+}$RNA $(20 \mu \mathrm{g})$ from mixed stage N2 worms was fractionated on an agarose gel, blotted onto Nytran (Schleicher \& Schuell), and hybridized to a labeled mpk-1 cDNA clone (pML20). The size (in kb) of RNA markers and the position of the two hybridizing RNA bands are shown. $(B)$ RNase protection analysis. To determine the relative abundances of the $1 \mathrm{X} 2$ and SLX2 RNAs, an RNase protection experiment was done using $50 \mu \mathrm{g}$ of yeast tRNA or $50 \mu \mathrm{g}$ of total RNA from mixed stage N2 worms. A 726-nucleotide antisense RNA probe was transcribed using a clone containing the $5^{\prime}$ end of the $1 \times 2$ cDNA (pML26) as a template. This RNA contained 673 nucleotides of $m p k-1$ sequence and 53 nucleotides of vector sequence. Hybridization of this probe to the IX2 and the SLX2 RNAs, followed by RNase cleavage of single-stranded regions, would be expected to give protected probe fragments of 673 and 595 nucleotides, respectively. The sizes (in nucleotides) of marker single-stranded DNA and the positions of the two protected probe fragments are shown. Because the sizes of the protected probe fragments (650 and 570 nucleotides) correspond closely to the sizes predicted above, it is likely that they result from hybridization to these RNA forms. However, mpk-1 RNA forms other than SLX2 that lack exon 1 would also be predicted to protect a 595-nucleotide probe fragment.

the $m p k-1(+)$ gene, because no rescued transgenic lines were obtained with a fragment that spanned the same genomic region but contained a frameshift mutation engineered into the mpk-1-coding region (Fig. 5B). Second, sequence analysis of $n 2521$ genomic DNA revealed that the $n 2521$ mutant contains a $\mathrm{C} \rightarrow \mathrm{T}$ substitution in the mpk-1 gene (Fig. 2); this substitution changes a leucine that is conserved in all known MAP kinases to a phenylalanine (Fig. 4). Third, independent studies by Y. Wu and M. Han (this issue) showed that the $m p k-1$ gene (also referred to as sur-1) contains a missense sequence change in the ku8 mutant. We showed that $n 2521$ failed to complement $k u 8$ for suppression of the $1 e t-60(g f)$ Muv phenotype, indicating that these two mutations are in the same complementation group. The finding that these two independently derived mutants are allelic and that both contain altered sequences in the mpk-1-coding region indicates that these $m p k-1$ sequence changes correspond to the $n 2521$ and $k u 8$ mutations.

The mpk-1(n2521) mutation affects ras-mediated induction of vulval cell fates

The mpk-1(n2521) mutation reduced the penetrance of the let-60(gf) Muv phenotype from $93 \%$ to $3 \%$ (Table 1; Fig. 6). Using Nomarski optics, we observed that the Pn.p cells in most mpk-1(n2521); let-60(gf) mutants expressed a wild-type pattern of cell lineages (Table 2). mpk-1(n2521) single mutant animals appeared to have wild-type vulvae when examined with a dissecting microscope, and the Pn.p cells in these mutants expressed a wild-type pattern of cell lineages when examined with Nomarski optics (Table 2). Thus, although mpk1(n2521) precludes P3.p, P4.p, and P8.p from adopting vulval fates in let-60(gf) animals, it does not preclude P5.p, P6.p, and P7.p, which are near the anchor cell, from adopting vulval fates in let $-60(g f)$ or let $-60(+)$ animals.

To understand how $m p k-1(+)$ functions in the vulval signaling pathway, it is important to determine how the n2521 mutation affects mpk-1 activity. Two observations suggest that $n 2521$ might cause a reduction of mpk-1 function. First, reduction-of-function mutations cause a decrease in gene activity that can be complemented by wild-type copies of the gene; the mpk1(n2521) phenotype is largely recessive, and transformation with mpk-1(+) DNA effectively rescued this phenotype (Table 1). Second, the $n 2521$ mutation changes a conserved leucine residue that lies near the region predicted by X-ray crystallographic studies to be the substrate-binding site (B. Goldsmith, pers. comm.). The n2521 mutation could well reduce MAP kinase activity by decreasing substrate binding. Because no extant deficiencies appear to delete $m p k-1$ (see Materials and methods), it has not been possible to use gene-dosage experiments to determine whether $n 2521$ behaves like a deficiency and hence is likely to be a null mutation. The n2521 mutation is not likely to cause increased gene activity (e.g., constitutive protein kinase activation) or to result in a novel $m p k-1$ function (e.g., phosphorylation of a new substratel, because the phenotypes caused by these types of mutations should not be rescued by injection of DNA containing the wild-type $m p k-1$ gene.

\section{mpk-1 appears to act downstream of let-60 ras}

The $n 1046$ mutation is similar to known oncogenic mutations in vertebrate ras, and thus it is likely that let$60(n 1046 g f)$ is constitutively active (Beitel et al. 1990). Consistent with this hypothesis, let- $60(\mathrm{gf})$ mutants display vulval induction in the absence of upstream signaling: $l e t-60(g f)$ mutants are Muv even when the inductive signal has been eliminated by ablating the anchor cell with laser microsurgery (Beitel et al. 1990). Furthermore, molecular analyses of lin-3, let-23, and sem-5 indicate that these genes encode proteins that would be expected to act upstream of $1 e t-60$, and strong reduction-of-function mutations in these three upstream signaling genes do not suppress the let-60(gf) Muv phenotype (Han et al. 1990; Clark et al. 1992b). Specifically, the lin-3 gene is expressed in the anchor cell and encodes a protein that is similar to EGF, suggesting that lin-3 may encode the anchor cell signal (Hill and Sternberg 1992). let-23 encodes a protein that is similar to EGF receptor (Aroian et al. 1990). Finally, the sem-5 protein is similar to verte- 


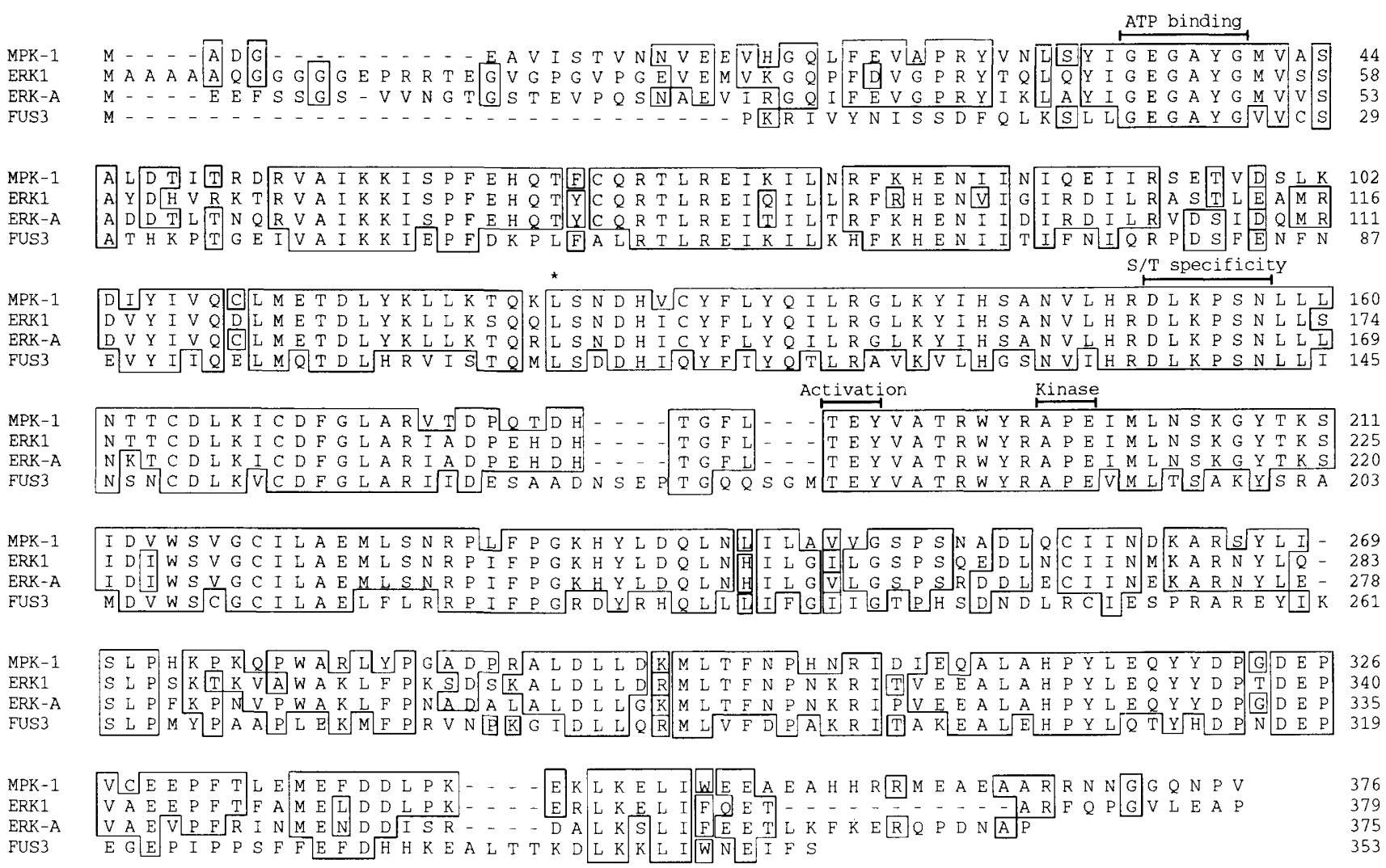

Figure 4. MPK-1 is similar to known MAP kinases. The predicted amino acid sequence of MPK-1 is compared with human ERK1 (Boulton 1990), D. melanogaster ERK-A (Biggs and Zipursky 1992), and S. cerevisiae FUS3 (Elion et al. 1990) kinases. Amino acids that are identical in two or more proteins are boxed; MPK-1 is $73 \%$ identical to ERK1 (273/376 identical residues), $73 \%$ identical to ERK-A (274/375 identical residues), and 48\% identical to FUS3 (169/353 identical residues). Domains with demonstrated functions are overlined. G-E-G-A-Y-G (ATP binding; amino acids 35-40) forms an ATP-binding site; the motif G-X-G-X-X-G is found in all kinases and many nucleotide-binding proteins (Hanks et al. 1988). A-P-E (Kinase; amino acids 198-200) is an essential part of the kinase catalytic domain (Hanks et al. 1988). Phosphorylation of the threonine and tyrosine residues in the T-E-Y sequence (Activation; amino acids 188-190) by MEK, a MAP kinase kinase, results in activation of ERK1 (Crews et al. 1992). The D-L-K-P-S-N sequence (S/T specificity; amino acids 152-157) indicates that the MPK-1 kinase has serine/threonine, rather than tyrosine, specificity (Hanks et al. 1988). The asterisk $\left({ }^{*}\right)$ indicates the leucine residue that was altered to a phenylalanine residue in the predicted mpk-1(n2521) protein sequence.

brate GRB2 (Clark et al. 1992a; Lowenstein et al. 1992), a protein that directly links activated receptor tyrosine kinases to proteins in the Ras complex (for review, see McCormick 1993).

Unlike mutations in upstream signaling genes, the $m p k-1$ (n2521) mutation prevented the ectopic vulval induction caused by let-60(gf) (Tables 1 and 2), suggesting that mpk-1 acts downstream of let-60 ras if these genes act in a linear pathway. Alternatively, let-60 and mpk-1 might act in parallel signaling pathways. The simplest interpretation of our results is that let-60 is only partially activated by the $n 1046$ mutation, and Pn.p cells far from the anchor cell (P3.p, P4.p, and P8.p) cannot express vulval cell fates if $m p k-1$ activity is reduced by the $n 2521$ mutation. In contrast, let-60 activity is strongly activated by the anchor cell signal in P5.p, P6.p, and P7.p, and the reduced activity of $m p k-1$ (n2521) is still sufficient for these Pn.p cells to adopt vulval fates.

We determined whether the mpk-1(n2521) mutation could suppress the Muv phenotype caused by mutations in lin-15, lin-31, and lin-1 (Table 1). lin-15 appears to act in the hyp7 hypodermal syncytium (Herman and Hedgecock 1990), and genetic studies suggest that lin-15 may act upstream of let-23 and let-60 (Han et al. 1990; Aroian and Sternberg 1991). The temperature-sensitive lin15(n765) allele partially reduces lin-15 activity and causes an incompletely penetrant Muv phenotype at $15^{\circ} \mathrm{C}$ (Ferguson and Horvitz 1985). The lin-15(n309) allele completely eliminates lin-15 activity (S. Clark, X. $\mathrm{Lu}$, and H.R. Horvitz, unpubl.) and results in a completely penetrant Muv phenotype. Table 1 shows that mpk-1(n2521) dramatically reduced the penetrance of the Muv phenotype caused by the let- $60(g f)$ mutation from $93 \%$ to $3 \%$. This result indicates that mpk-1 activity is necessary to transduce the effects of 1 et- 60 ras activation and suggests that $m p k-1$ acts downstream of let60 ras. In contrast, the mpk-1(n2521) mutation reduced only slightly the penetrance of the Muv phenotype 
Table 1. Interactions between mpk-1 and vulval determination genes: penetrances of Muv phenotypes

\begin{tabular}{lc}
\hline Genotype $^{\mathrm{a}}$ & $\begin{array}{c}\text { Percent } \\
\text { Muv }(n)^{\mathrm{b}}\end{array}$ \\
\hline let-60(gf) & $93(674)$ \\
mpk-1(n2521); let-60(gf) & $3(1912)$ \\
mpk-1(n2521)/+; let-60(gf) ${ }^{\mathrm{c}}$ & $83(149)$ \\
mpk-1(n2521); let-60(gf); gaEx31 & $93(140)$ \\
lin-15(n309) & $100(206)$ \\
mpk-1(n2521); lin-15(n309) & $100(191)$ \\
dpy-17; lin-15(n765) & $99(290)$ \\
mpk-1(n2521) dpy-17; lin-15(n765) & $80(428)$ \\
dpy-17; lin-15(n765) & $16(121)$ \\
mpk-1(n2521) dpy-17; lin-15(n765) & $8(167)$ \\
lin-1 & $74(633)$ \\
mpk-1(n2521); lin-1 & $82(490)$ \\
lin-31 & $74(207)$ \\
lin-31; mpk-1(n2521) & $72(215)$ \\
\hline
\end{tabular}

${ }^{a} m p k-1(n 2521)$ reduced the penetrance of the Muv phenotype caused by let-60(gf) and lin-15(n765) but did not affect the penetrance of the Muv phenotype caused by lin-15(n309), lin-1, or lin-31. Animals were scored at $20^{\circ} \mathrm{C}$. Except where noted, let-60(gf) refers to let-60(n1046). Alleles used: let-60(n1046, n1700), dpy-17(e164), lin-1(e1275), and lin-31(n1053). The lin31 and lin-15(n309) alleles are strong loss-of-function, or null, alleles (Ferguson and Horvitz 1985; Miller et al. 1993); the lin15(n765) and lin-1 alleles are partial reduction-of-function mutations (Ferguson and Horvitz 1985).

$\mathrm{b}(n)$ Number of animals scored.

'Genotype mpk-1(n2521)/dpy-17; let-60(n1046)/let-60(n1700). $n 1046$ and $n 1700$ are independently derived mutations that result in the same amino acid substitution (Beitel et al. 1990). $\mathrm{d}_{g a E x} 31$ is an extrachromosomal array containing mpk-1(+) DNA (see Materials and methods).

${ }^{\text {eScored at }} 15^{\circ} \mathrm{C}$.

caused by the weak $\operatorname{lin}-15(n 765)$ mutation from $99 \%$ to $80 \%$ at $20^{\circ} \mathrm{C}$ and from $16 \%$ to $8 \%$ at $15^{\circ} \mathrm{C}$, and did not reduce the $100 \%$ Muv penetrance caused by the lin15(n309) mutation. These observations suggest that the lin-15 Muv phenotype is not mediated solely by the activation of let-60 ras because the lin-15 Muv phenotype seems not to be as sensitive to the mpk-1(n2521) mutation as is the let-60 Muv phenotype.

lin-1 and lin-31 loss-of-function mutations also cause a Muv phenotype. lin-31 is required for the proper choice of cell fates, as loss-of-function mutations in lin-31 result in a deregulated mutant phenotype in which each Pn.p cell can express any of the three potential cell fates (Miller et al. 1993). lin-31 encodes a putative transcription factor with a DNA-binding domain similar to the HNF-3/fork head DNA-binding domain (Miller et al. 1993|. Loss-of-function mutations in lin-1 cause P3.p, P4.p, and P8.p to adopt vulval cell fates (Horvitz and Sulston 1980). mpk-1(n2521) did not suppress the lin-1 or lin-31 mutant phenotypes (Table 1). These data are consistent with a pathway in which mpk-1 acts upstream of $l i n-1$ and lin-31. However, because mpk1(n2521) may not be a complete loss-of-function mutation, it is not possible at this point to assign unambigu- ously the order of action of mpk-1, lin-15, lin-31, and lin-1.

\section{Mosaic analysis of mpk-1}

Although it has been hypothesized that the genes in the receptor tyrosine kinase pathway mediated by let 60 ras act in the Pn.p cells /for review, see Horvitz and Sternberg 1991), this hypothesis has not been tested. To determine which cells require $m p k-1(+)$ function, we used a recently developed method of mosaic analysis. In this method, which is likely to be widely applicable, cloned DNA fragments containing a gene of interest (such as $m p k-1)$ and the cell autonomous marker gene $n c l-1$ are used to form a mitotically unstable extrachromosomal array (L. Miller, D. Waring, and S. Kim, in prep.). To determine which cells require mpk-1 function, transgenic animals were generated that had chromosomal mutations in $m p k-1$ and $n c l-1$ and carried wild-type copies of these genes on an extrachromosomal array. Mosaic animals were identified by screening for animals in which some, but not all, cells had large nucleoli, the Ncl mutant phenotype. The pattern of cell divisions leading to the generation of every cell in C. elegans is known and is largely invariant among different individuals (Sulston

\section{A}

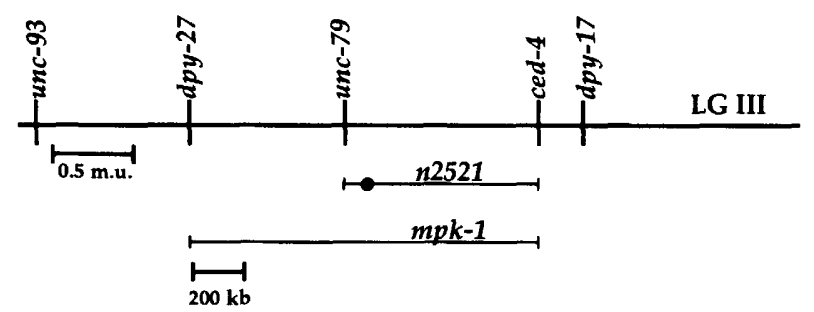

B

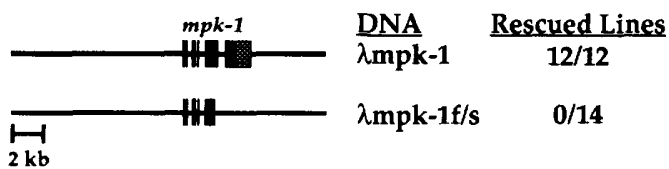

Figure 5. $n 2521$ is an allele of mpk-1. (A) Genetic mapping experiments showed that the position of the $n 2521$ mutation is between unc-79 and ced-4 on linkage group III. (O) The likely position of $n 2521$ within this interval based on 3- and 4-factor map data (see Materials and methods). The mpk-1 gene was localized on the $C$. elegans genome physical map between the cloned genes $d p y-27$ and ced-4. $(B)$ DNA containing the mpk$1(+)$ gene rescued the $n 2521$ phenotype. The lines represent 18 $\mathrm{kb}$ of genomic DNA contained in $\lambda \mathrm{mpk}-1$ and $\lambda \mathrm{mpk}-1 \mathrm{f} / \mathrm{s}$. Boxes in $\lambda$ mpk-1 represent exons $2-7$, as described in Fig. 2 . A frameshift mutation $(\mathrm{f} / \mathrm{s})$ introduced into $\lambda \mathrm{mpk}-1$ shortens the coding region in the construct $\lambda \mathrm{mpk}-1 \mathrm{f} / \mathrm{s}$ as indicated /see Materials and methods). The numbers of independently derived lines rescued for the $n 2521$ mutant phenotype by $\lambda \mathrm{mpk}-1$ or $\lambda \mathrm{mpk}-1 \mathrm{f} / \mathrm{s}$ DNA in germ-line transformation experiments are shown. 

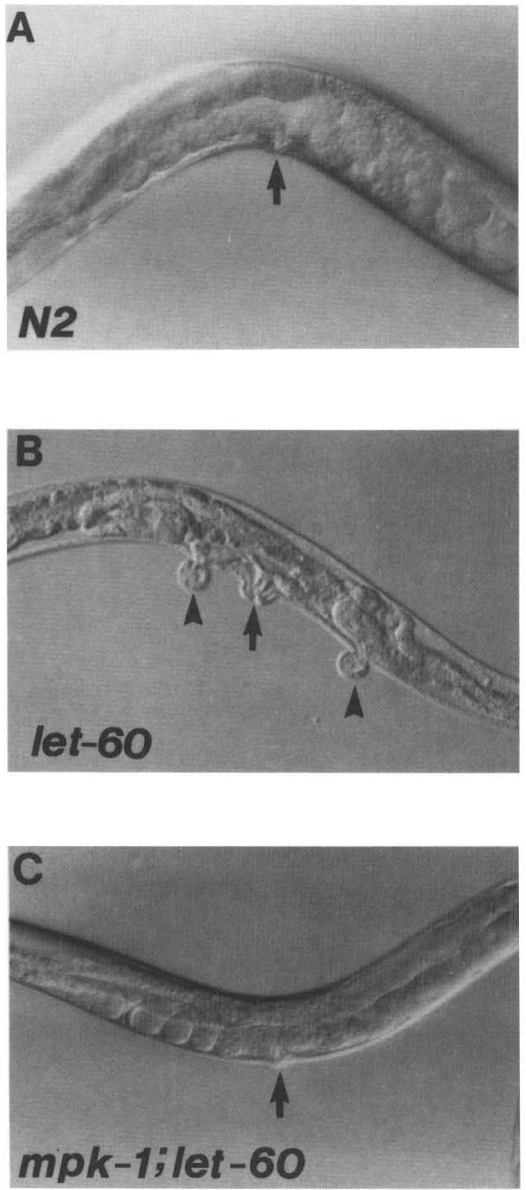

Figure 6. mpk-1 vulval phenotypes. $(A)$ A wild-type adult hermaphrodite viewed with Nomarski optics. An arrow indicates the vulva. $(B)$ A let-60(gf) adult hermaphrodite. The ventral protrusions of vulval tissue (arrowheads) constitute the Muv phenotype. (C) A mpk-1(n2521); let-60(gf) hermaphrodite. This animal has wild-type vulval morphology, and no ventral protrusions are visible.

and Horvitz 1977; Sulston et al. 1983). We found that the Ncl cells were usually derived from a single clone of somatic cells, suggesting that the extrachromosomal array was lost at a specific cell division that generated a single progenitor cell lacking the array. If so, all descendants of this progenitor cell should lack both the $\mathrm{ncl}$ $1(+)$ and the $m p k-1(+)$ genes.

The results shown in Figure 7 indicate that the mpk-1 gene was required in the lineage that gives rise to the Pn.p cells. If none of the Pn.p cells contained the array (loss at $\mathrm{AB}$ or $\mathrm{AB} . \mathrm{p}$ ), then animals exhibited the mpk1(n2521) mutant phenotype; if the rescuing array was present in the Pn.p cells, then the mpk-1(n2521) mutant phenotype was rescued, even if the array was absent in the anchor cell (loss at EMS or MS) or in lineages that give rise to the majority of the hypodermal syncytium nuclei (loss at $\mathrm{AB} . \mathrm{a}$ or $\mathrm{P} 2$ ). These results suggest that mpk-1 functions in the Pn.p cells to transduce the signal generated by let -60 ras.

\section{Discussion}

In this report we have presented a molecular and genetic analysis of mpk-1, a C. elegans MAP kinase homolog. The protein encoded by $m p k-1$ is $73 \%$ identical to the human MAP kinase ERK1 and contains all of the canonical domains associated with known MAP kinases. Our genetic results indicate that $m p k-1$ acts in the receptor tyrosine kinase signal transduction pathway that controls vulval induction. Independently, $\mathrm{Wu}$ and $\mathrm{Han}$ /this issue) have obtained similar and complementary results on the role of the same MAP kinase gene /which they refer to as sur-1) in vulval development.

\section{mpk-1 activity is required in Pn.p cells}

The development of the vulva appears to involve signaling among the anchor cell, the hyp7 hypodermal syncytium, and the Pn.p cells. Thus, to understand how a gene functions during vulval development, it is important to establish which tissue requires the activity of that gene. Genes involved in the production or release of a signal should act nonautonomously; their activities should be required in signaling tissues such as the anchor cell or the hypodermal syncytium. For example, lin-15 activity appears to be required in the hyp 7 hypodermal syncytium (Herman and Hedgecock 1990). Genes involved in the reception, transduction, or cellular response to extracellular signals should act cell autonomously; their activities should be required in the Pn.p cells. On the basis of genetic and molecular studies, it has been predicted that let-23 EGFR and downstream genes act cell autonomously. Our findings establish that $m p k-1$ acts in the Pn.p cells. In mosaic animals, the mpk-1 mutant phenotype correlated with the presence or absence of mpk-1 rescuing activity in Pn.p cells, but not with the presence or absence of $m p k-1$ rescuing activity in the anchor cell or the hyp7 hypodermal syncytium. These results suggest that mpk-1 functions in the Pn.p cells to transduce the inductive signal of the anchor cell.

Table 2. Pn.p cell lineages

\begin{tabular}{lccccccc}
\hline & & \multicolumn{7}{c}{ Cell fate $^{\mathrm{a}}$} \\
\cline { 3 - 8 } Genotype & $\mathrm{N}^{\mathrm{b}}$ & P3.p & P4.p & P5.p & P6.p & P7.p & P8.p \\
\hline Wild-type & many $^{\mathrm{c}}$ & 3 & 3 & 2 & 1 & 2 & 3 \\
let-60(gf) & $12^{\mathrm{d}}$ & $1 / 2$ & $1 / 2$ & 2 & 1 & 2 & $1 / 2$ \\
$\begin{array}{l}\text { mpk-1(n2521); } \\
\quad\end{array}$ & & & & & & \\
let-60(gf) & $10^{\mathrm{e}}$ & 3 & 3 & 2 & 1 & 2 & 3 \\
mpk-1(n2521) & 10 & 3 & 3 & 2 & 1 & 2 & 3 \\
\hline
\end{tabular}

The numerals 1,2 , and 3 refer to primary, secondary, and tertiary, respectively.

${ }^{b}$ Number of animals observed.

'The wild-type lineage of $\mathrm{P}(3-8) \cdot \mathrm{p}$ is from Sulston and Horvitz \{1977).

dData for let-60(n1046) homozygotes are from Ferguson (1985): P3.p expressed an induced $\left(1^{\circ}\right.$ or $\left.2^{\circ}\right)$ fate in $9 / 12$ animals, P4.p in $10 / 12$ animals, and P8.p in $7 / 12$ animals.

eP3.p adopted a $2^{\circ}$ lineage in one animal, and P4.p adopted a partially induced fate (i.e., generated three descendants) in another animal. 


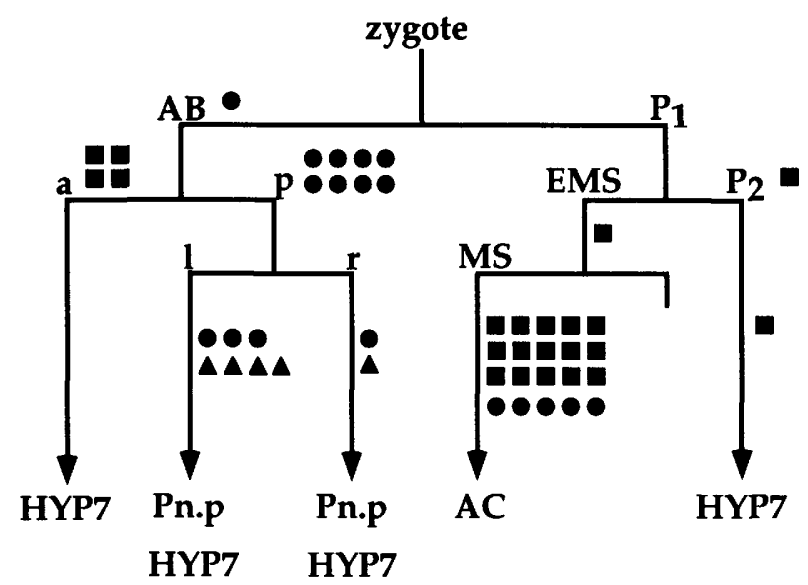

Figure 7. Mosaic analysis of $m p k-1$. Vertical lines represent the lineage leading to the named cells; horizontal lines represent cell divisions. Circles, squares, and triangles each represent one mosaic animal. Symbols are positioned next to the cell in the lineage that we inferred to have lost the extrachromosomal array, or next to the vertical line in cases in which the array was inferred to have been lost at a division between the two connected cells. (O) Non-Muv animals with a wild-type vulva [the mpk-1(n2521); let-60(gf) phenotype); ( $\mid$ ) a strongly Muv animal [the $\mathrm{mpk}-1(+)$; let-60 (gf) phenotype]; (A) a weakly Muv animal that displayed one small, ectopic pseudovulval protrusion [partial mpk-1(n2521)] phenotype. The data are most consistent with the conclusion that $m p k-1$ function is required in the descendants of AB.p but not in the descendants of AB.a or P1. Only two tissues known to be involved in vulval induction are descendants of AB.p (the Pn.p cells and the hyp7 hypodermal syncytium). Thus, mpk-1 activity is most likely required in one of these two tissues. $m p k-1$ activity is probably not required in the hyp 7 hypodermal syncytium because only 46 of 133 nuclei in this syncytium are derived from AB.p. If the various nuclei contained in the hyp7 hypodermal syncytium are functionally equivalent, $m p k-1$ activity would also be required in AB.a and $\mathrm{P} 2$, which contribute 75 and 12 nuclei to this syncytium, respectively (Sulston et al. 1983). A site of action in the Pn.p cells is more likely because all of the Pn.p cells are derived from AB.p. Furthermore, $m p k-1$ activity appeared to be partially required in both AB.pl and AB.pr; a weak Muv phenotype was observed in 5/9 animals that lacked the array in one of these cells. This result supports the hypothesis that $m p k-1$ activity is required in the Pn.p cells, as these two cells each generate three Pn.p cells. In the parental transformant strain, $23 \%$ of the nonUnc animals were non-Muv; because of partial penetrance of the let-60(n1046gf) Muv phenotype and incomplete rescue of the mpk-1(n2521) phenotype by the extrachromosomal array. Twenty-five percent $(5 / 20)$ of the animals that lost the array in MS were non-Muv; because this frequency is similar to that of the parental transformant strain, $m p k-1$ activity does not appear to be required in MS.

mpk-1 may act downstream of let-60 ras

The mpk-1(n2521) mutation suppressed the Muv phenotype caused by a gain-of-function mutation in let-60 ras. This result suggests that mpk-1 acts at a step that is downstream of let- 60 ras, because defects in the signaling pathway at upstream steps do not suppress the let- 60(gf) Muv phenotype. This inferred gene order is consistent with results obtained in studies of vertebrate cells, because MAP kinases are phosphorylated and thereby activated in response to Ras activation (Anderson et al. 1990; deVries-Smits et al. 1992). The simplest interpretation of our genetic results is that the interaction between let- 60 and mpk-1 in C. elegans vulval signaling is similar to the interaction between Ras and MAP kinase in vertebrate signaling. If so, constitutive activation of let -60 by the $n 1046$ mutation would result in a Muv phenotype as a result of activation of $m p k-1$ function in all six Pn.p cells. In $m p k-1$ (n2521); let-60(gf) animals, increased mpk-1 activity caused by the let$60(g f)$ mutation presumably is compensated by reduced activity caused by the mpk-1(n2521) mutation.

Our results suggest that let-60 ras may be activated more strongly by the anchor cell signal than by the let$60(\mathrm{gf})$ mutation. In either mpk-1(n2521) or mpk1(n2521); let-60(gf) animals, the mpk-1(n2521) mutation did not prevent the expression of induced vulval cell fates by Pn.p cells close to the anchor cell (P5.p, P6.p, and P7.p), suggesting that let-60 ras is strongly activated in these cells by the anchor cell signal and is able to induce vulval cell fates despite a reduction in mpk-1 activity caused by the $n 2521$ mutation. In contrast, in mpk1(n2521); let-60(gf) animals, the mpk-1(n2521) mutation reduced expression of vulval cell fates by Pn.p cells far from the anchor cell (P3.p, P4.p, and P8.p), suggesting that let-60 ras is weakly activated by the let-60(gf) mutation and that this weak activation is not adequate to induce vulval cell fates when $m p k-1$ (n2521) activity is reduced by $n 2521$.

Is the activity of mpk-1 required to mediate all of the consequences of let-60 ras activity in the vulval signaling pathway? If so, mutations that strongly reduce mpk-1 activity should completely block the effects of let-60 ras activation, resulting in a phenotype similar to that caused by strong reduction-of-function let-60 ras mutations (vulvaless). However, mpk-1(n2521) mutants had normal vulval induction, indicating that ras-mediated vulval signaling can occur in mpk-1(n2521) mutants. One possible explanation for this observation is that $m p k-1$ is required for all let-60 ras-mediated vulval signaling but the $n 2521$ mutation only partially reduces mpk-1 activity. In that case, mutations that further reduce $m p k-1$ activity would prevent vulval induction. Another possibility is that $m p k-1$ is required for only some aspects of let-60 ras-mediated vulval signaling, because the signaling pathway branches between let-60 ras and mpk-1. In that case, the mpk-1(n2521) mutation may eliminate the activity of the mpk-1 gene.

A related issue is whether mpk-1 mediates the consequences of let-60 ras activation in all other cell types. If so, elimination of mpk-1 activity should cause a phenotype similar to the phenotype caused by elimination of let-60 ras activity (lethality). However, mpk-1(n2521) mutants are viable, suggesting again that the n2521 allele is a partial reduction-of-function mutation or that genes other than mpk-1 can mediate let-60 ras activity in other cells. 
mpk-1 functions to activate the vulval signaling pathway

Although Ras clearly stimulates MAP kinase activity in cultured cells (deVries-Smits et al. 1992), the physiological relevance of this MAP kinase activation has been difficult to assess. Biochemical studies have shown that MAP kinases can phosphorylate many different proteins (for review, see Blenis 1993). In many cases, phosphorylation by MAP kinases does not appear to alter the in vitro activities of target proteins. In some cases, phosphorylation by MAP kinases stimulates the in vitro activity of target proteins, whereas in other cases, MAP kinases have an inhibitory effect. Furthermore, several upstream signal transduction molecules (such as EGFR, Raf, and MEK) are MAP kinase substrates, suggesting that MAP kinases might be feedback regulators of signaling pathways. It has been difficult to establish the relative importance of the stimulatory and inhibitory roles that MAP kinases have in vitro on cellular signaling pathways in vivo.

One way to investigate the role of MAP kinases in signaling pathways in vivo is to use genetic analysis. Our results indicate that in C. elegans, mpk-1 activity is required for ectopic vulval induction caused by an activated let-60 ras gene. The simplest interpretation of these results is that mpk-1 is involved in transducing the signal from both activated and normal ras genes. This interpretation supports the hypothesis that $m p k-1$ acts to stimulate the vulval signaling pathway.

Alternatively, $m p k-1$ might transduce signals from the let- 60 ras gene activated by the $n 1046$ mutation but not from the wild-type let-60 ras gene. This possibility seems unlikely for two reasons. First, the let-60(gf) Muv phenotype can result from an increase in the dosage of the wild-type let-60 ras gene (Beitel et al. 1990; Han et al. 1990). Second, mpk-1(n2521) partially suppresses the lin-15 Muv phenotype, and vulval induction in this mutant is dependent on wild-type let-60 activity (Han et al. 1990; Clark et al. 1992b).

Recent genetic studies of other animals are consistent with our conclusions regarding the in vivo function of MAP kinase genes. Expression of human MAP kinase antisense RNA or putative dominant-negative forms of MAP kinase protein can inhibit proliferation of vertebrate fibroblasts, indicating that MAP kinases may normally stimulate proliferation (Pages et al. 1993). In Drosophila, a MAP kinase homolog has recently been shown to be required for induction by ras-mediated signaling pathways, including the pathway resulting in the induction of the R7 photoreceptor cell in the eye (E. Hafen and S.L. Zipursky, pers. comm.).

How does activation of the vulval signaling pathway ultimately lead to the expression of vulval cell fates? It is likely that vulval differentiation involves changes in transcriptional activity, and many vertebrate transcription factors appear to be MAP kinase substrates. In vulval development, LIN-31 is a candidate substrate for MPK-1 because LIN-31 is a putative transcription factor with an HNF-3/fork head DNA-binding domain that has a consensus MAP kinase phosphorylation site (Pro-IleThr-Pro; amino acids 143-146) (Alvarez et al. 1991; Miller et al. 1993). Genetic analysis indicates that lin-31 may regulate the specification of vulval cell fates. The identification and molecular characterization of genes that act downstream of $m p k-1$ are likely to illuminate how signaling pathways can redirect transcriptional activity and lead to the expression of new cell fates.

\section{Materials and methods}

General methods and strains

C. elegans strains were maintained and handled using standard techniques (Brenner 1974). Animals were grown at $20^{\circ} \mathrm{C}$ unless noted otherwise. The animals designated as wild-type were $C$. elegans, variety Bristol, strain N2 (Brenner 1974). Unless noted otherwise, mutations used are described by Wood (1988). Genetic markers used in this study are listed below: (LGI), unc29(e1072); (LGII), lin-31(n1053) (Ferguson and Horvitz 1985); (LGIII), dpy-27(y57) (gift from P. Chuang, University of California, Berkeley), unc-79(e1068), mpk-1(n2521) (this work), ced4(n1162), dpy-17(e164), ncl-1(e1942), unc-32(e189), nDf11 (Greenwald and Horvitz 1980), yDf10 (gift from P. Chuang) (LGIV), lin-1(e1275), let-60(n1046gf, n1700gf) (Beitel et al. 1990). (LGX) $\operatorname{lin}-15(n 765, n 309)$. In this paper, let-60(gf) refers to let-60(n1046).

\section{Genetic analyses}

In a population of let-60(n1046) mutants, $93 \%$ of the animals are Muv. To isolate mutations that suppress this Muv phenotype, let-60(n1046) hermaphrodites were mutagenized with ethyl methanesulfonate (EMS) (Brenner 1974). $F_{1}$ self progeny (2794) of mutagenized hermaphrodites were picked to separate plates, and $F_{2}$ self progeny were examined. If $F_{1}$ animals segregated $>25 \%$ non-Muv $F_{2}$ progeny, several non-Muv $F_{2}$ animals were picked to separate plates, and $\mathrm{F}_{3}$ self progeny were examined. If $\mathrm{F}_{2}$ animals segregated $>90 \%$ non-Muv $\mathrm{F}_{3}$ progeny, the strain was investigated further. In this way, 33 independently derived mutations were identified that reduced the penetrance of the Muv phenotype so that in a population, $<10 \%$ of the animals were Muv. For this screen, animals were raised at $22.5^{\circ} \mathrm{C}$. Ten additional suppressor mutations that meet these criteria were identified in a related screen (Beitel et al. 1990). To analyze these 43 mutations, each was assigned to a linkage group (Brenner 1974), and mutations on the same linkage group were tested for complementation of the suppression phenotype. This analysis showed that the mutations represent 21 complementation groups. A detailed description of this analysis will be presented elsewhere (K. Kornfeld and H.R. Horvitz, in prep.). n2521 was the only allele in its complementation group.

The following data established that $\mathrm{n} 2521$ lies between unc79 and ced-4 on linkage group III. Of the Unc non-Dpy progeny of mpk-1(n2521)/dpy-27 unc-79; let-60(gf) hermaphrodites, $0 / 10$ segregated non-Muv progeny. This result indicates that $m p k-1(n 2521)$ is likely to be located to the right of unc-79. Of the Unc non-Dpy progeny of mpk-1(n2521)/unc-79 ced-4 dpy17; let-60(gf) hermaphrodites, $1 / 9$ segregated non-Muv non-Ced progeny, 6/9 segregated Muv non-Ced progeny, and 2/9 segregated Muv Ced progeny. Of the Dpy non-Unc progeny of these hermaphrodites, $9 / 11$ segregated non-Muv Ced progeny and $2 / 11$ segregated non-Muv non-Ced progeny. Thus, of 16 recombination events between unc-79 and ced-4, 1 occurred between unc-79 and mpk-1, and 15 occurred between mpk-1 and ced-4. 
As shown in Figure 5, these data suggest that mpk-1 lies between unc-79 and ced-4, and that mpk-1 is positioned substantially closer to unc-79 than ced-4.

The mpk-1(n2521); lin-1 strain was constructed by mating dpy-27 unc-32/+ +; lin-1/+ males and mpk-1(n2521) hermaphrodites. Cross progeny hermaphrodites were placed on separate plates. Using animals that segregated Dpy Unc and Muv progeny, first lin-1 homozygous animals were identified because they segregated $>50 \%$ Muv progeny, and then $\mathrm{mpk}$ 1(n2521) homozygous animals were identified because they failed to segregate Dpy Unc progeny. An analogous method was used to construct the mpk-1(n2521); lin-31 strain. The mpk1(n2521) dpy-17; lin-15(n765) strain was constructed by mating mpk-1(n2521) dpy-17/ + + males and lin-15(n765) hermaphrodites. Cross-progeny hermaphrodites were placed on separate plates. Using animals that segregated Dpy progeny, first lin$15(n 765)$ homozygous animals were identified because they seg. regated $>50 \%$ Muv progeny, and then homozygous $m p k-1$ and dpy-17 animals were identified by picking Dpy progeny. The mpk-1(n2521); lin-15(n309) strain was constructed by mating mpk-1(n2521) males and unc-79 dpy-17/ + + ; lin-15(n309) hermaphrodites. Cross-progeny hermaphrodites were placed on separate plates. Using animals that segregated Unc Dpy progeny, first lin-15(n309) homozygous animals were identified because they segregated $>50 \%$ Muv progeny, then $m p k-1$ (n2521) homozygous animals were identified because they failed to segregate Unc Dpy progeny. For each of the double mutants, similar results were obtained from two independently constructed strains.

The deficiencies $y D f 10$ and $n D f 11$ delete unc- 79 but not ced-4 (Ellis and Horvitz 1986; P. Chuang, pers. comm.). To determine whether the deficiencies delete $m p k-1$, DNA from individual dead eggs was amplified using primers from the mpk-1-coding region and PCR amplification (Williams et al. 1992). A 340-bp fragment of $m p k-1$ DNA was amplified from $12 / 12$ yDf10 eggs and $9 / 9 \mathrm{nDf11}$ eggs (data not shown), suggesting that neither deficiency deletes mpk-1. Although some dead eggs may not have been homozygous for these deficiencies, the conclusion is valid if any of the dead eggs were deficiency homozygotes.

In an attempt to isolate additional $m p k-1$ alleles, we performed a genetic screen to isolate mutations that could cause an egg-laying defective or vulvaless phenotype in trans to mpk1(n2521) and failed to identify any new mpk-1 alleles after screening 65,000 EMS-mutagenized haploid genomes. Because null mutations usually occur at a frequency of 1 in 2000 EMSmutagenized genomes (Brenner 1974; Meneely and Herman 1979; Greenwald and Horvitz 1980), the failure to recover mpk-1 alleles in this large genetic screen suggests that animals with the genotype $m p k-1(n 2521) / m p k-1$ (null) do not display either an egg-laying defective or a vulvaless mutant phenotype.

\section{Determination of Pn.p cell lineages}

Pn.p cell lineages of mpk-1(n2521); let-60(n1046) and mpk1(n2521) mutants were determined by direct observation using Nomarski optics, as described previously (Sulston and Horvitz 1977). Fates of $1^{\circ}, 2^{\circ}$, and $3^{\circ}$ were assigned using the criteria established by Sternberg and Horvitz (1986), and generally denote cases in which the Pn.p cell generated 8, 7, or 2 descendants, respectively.

\section{Germ-line transformation experiments}

Germ-line transformation experiments were done according to the method of Fire (1986), as modified by Mello (1991). mpk1(n2521); let-60(n1046) mutants were coinjected with mpk-1
DNA $(\lambda \mathrm{mpk}-1$ at $50 \mu \mathrm{g} / \mathrm{ml}$ or $\lambda \mathrm{mpk}-1 \mathrm{f} / \mathrm{s}$ at $100 \mu \mathrm{g} / \mathrm{ml})$ and DNA carrying the dominant transformation marker mutation rol-6(su1006) (plasmid pRF4 at $50 \mu \mathrm{g} / \mathrm{ml}$ )(Kramer et al. 1990). Transgenic animals, identified by the Rol phenotype conferred by rol-6, typically maintain the coinjected DNA as an extrachromosomal array. An array containing $\lambda$ mpk- 1 and pRF4 was designated gaEx $31 . \mathrm{F}_{2}$ populations in which $<50 \%$ of Rol progeny were Muv were defined as rescued for the $n 2521$ suppression phenotype.

\section{Mosaic analysis}

unc-29(e1072) I; mpk-1(n2521) ncl-1 (e1942) III; let-60(n1046gf) $I V$ animals were transformed by germ-line injection of DNA containing unc-29(+) (cosmid C45D10), mpk-1 $(+)(\lambda \mathrm{mpk}-1)$, and $n \mathrm{cl}-1(+)$ (cosmid C33C3) at concentrations of 50-100 $\mu \mathrm{g} /$ $\mathrm{ml}$ each. The injected DNA formed an extrachromosomal array, gaEx26 [unc-29(+), mpk-1(+), ncl-1(+)] that is occasionally lost during mitosis, yielding mosaic animals. Animals mosaic for the enlarged nucleoli phenotype ( $\mathrm{Ncl}$ ) caused by the $\mathrm{ncl}-1$ mutation (E. Hedgecock, pers. comm.; for review, see Herman 1989) were identified using Nomarski optics to screen 6155 L3 or L4 stage animals. The progenitor cell that lost the array was inferred from the pattern of descendant cells that displayed the $\mathrm{Ncl}$ phenotype. The use of $n c l-1(+)$ as a cell-autonomous mosaic marker on an extrachromosomal array will be described in more detail elsewhere (L. Miller, D. Waring, and S. Kim, in prep.). The Ncl phenotype of the anchor cell was scored directly. Because the Ncl phenotype cannot be scored easily in Pn.p cells, the $\mathrm{Ncl}$ phenotypes of the neurons derived from the Pn.a cells (sister cells to the Pn.p cells) were used to infer the probable genotypes of the Pn.p cells. Several sets of cells were used to determine losses of the array in the hyp7 hypodermal syncytium, a tissue that is derived from several branches of the lineage (AB.a, AB.p, EMS, MS, P2). Pharyngeal neurons (I1L, I1R, I2L, I2R, I5, NSML, NSMR, M2L, M2R, M3L, M3R, MCL, MCR, MI) were used to identify loss of the array at AB.a. Postdeirids, the excretory cell, and the Pn.a-derived neurons were used to identify loss of the array at AB.p or later. Ring neurons are derived from both $\mathrm{AB}$.a and AB.p, and loss of the extrachromosomal array in either of these cells causes approximately half of the ring neurons to express a $\mathrm{Ncl}$ phenotype. Body muscles, pharyngeal neurons $(13, \mathrm{I} 4, \mathrm{I} 6, \mathrm{M} 1, \mathrm{M} 4, \mathrm{M} 5)$, distal tip cells, and the anchor cell were used to identify loss of the array at EMS, MS, or cells later in the EMS lineage. Body muscles and germline transmission were used to identify loss of the array at P2 or later. Adult mosaic animals were scored for the presence of ectopic pseudovulvae.

\section{Manipulation of DNA and RNA}

Molecular biological techniques were done as described by Sambrook et al. (1989), with minor modifications. The sequences of degenerate oligonucleotide primers used to isolate $m p k-1$ and mpk-2 were $5^{\prime}$-CTC GGA TCC GTN GCN AT(C,T,A) AA(G,A) $\mathrm{AA}(\mathrm{G}, \mathrm{A}) \mathrm{AT}-3^{\prime}$ (amino acid sequence VAIKKI) and 5'-CTC GGA TCC TCN GGN GCN C(G,T)(G,A) TAC CA-3' (amino acid sequence WYRAPE); the 5' ends of the primers begin with a 9-nucleotide sequence used for subsequent cloning steps (underlined). PCR amplifications were performed on C. elegans genomic DNA and cDNA using standard protocols (Innis et al. 1990). Annealing was carried out at $40^{\circ} \mathrm{C}$ for cycles $1-3$, and $50^{\circ} \mathrm{C}$ for cycles $4-35$. Denaturation and extension were conducted at $94^{\circ} \mathrm{C}$ and $72^{\circ} \mathrm{C}$, respectively, for all cycles. PCR products were cloned in the pCRII vector (Invitrogen), and their sequences were determined using Sequenase v. 2.0 T7 DNA 
polymerase (U.S. Biochemical). To isolate an $m p k-1$ genomic DNA clone, the 940-bp insert of a mpk-1 PCR-derived clone (pML10) was used as a probe to isolate a bacteriophage that contains an 18-kb genomic DNA fragment ( $\lambda$ mpk-1); the library that was used has $C$. elegans genomic DNA cloned in bacteriophage $\lambda$ EMBL3 (Frischauf et al. 1983). To isolate mpk-1 cDNA clones, a 1.8-kb BamHI/HindIII genomic DNA fragment containing most of exons 2-6 (Fig. 2B) was used as a probe to isolate bacteriophages that contain mpk-1 cDNA inserts; the cDNA libraries were constructed using $\lambda$ gt 10 (Young and Davis 1983) and $\lambda Z A P$ (Short et al. 1988) cloning vectors. We determined the nucleotide sequences of a $4-\mathrm{kb}$ genomic DNA fragment that extended from the left HindIII site to 800 bp beyond the right HindIII site (Fig. 2B) and the inserts in two cDNA clones (pML20 and pML25). mpk-1 exons 2-7 span $3.2 \mathrm{~kb}$ within the sequenced genomic DNA region; DNA containing exon 1 did not hybridize to the $18-\mathrm{kb}$ insert of $\lambda \mathrm{mpk}-1$, indicating that exon 1 is at least $7 \mathrm{~kb}$ removed from exon 2 .

In the reverse transcriptase-PCR experiment used to define the $5^{\prime}$ end of mpk-1, a primer complementary to the SLl transspliced leader sequence $\left(5^{\prime}\right.$-GGT TTA ATT ACC CAA GTT TGA G-3') and an antisense $m p k-1$ primer spanning nucleotides 914-937 (Fig. 2A) were used to amplify cDNA derived from 10 ng of mixed stage poly $(A)^{+}$RNA; $^{2} \%$ of this reaction was used in a second PCR with the SLl primer and an antisense mpk-1 primer spanning nucleotides 718-739 (Fig. 2A). Southern blot analysis identified a single $\sim 700 \mathrm{bp}$ fragment from this reaction that hybridized with a 1.8-kb BamHI/HindIII genomic DNA fragment containing most of exons 2-6 (Fig. 2B). This fragment was cloned in pCRII, and sequence analysis showed that it has the 22-nucleotide SL1 sequence attached to nucleotides 79-739 of the composite cDNA. To characterize the n2521 allele, the nucleotide sequence of the complete coding region of the SLX2 transcript (exons 2-7) was determined. PCR-amplified fragments of DNA from mpk-1(n2521) mutants were cloned in pCRII, and the nucleotide sequence of at least two independent clones was determined. The $\mathrm{C} \rightarrow \mathrm{T}$ transition at nucleotide 448 was detected in $5 / 5$ clones derived from two independent PCR amplifications. $\lambda \mathrm{mpk}-1 \mathrm{f} / \mathrm{s}$ is predicted to have a frameshift at amino acid 248 that creates a stop codon at amino acid 255 of mpk-1. This construct was made by cleaving $\lambda$ mpk-1 with BamHI, which cuts at a unique site in this clone corresponding to nucleotide 821 . Overhanging termini were removed with T4 DNA polymerase, and the blunt ends were ligated with T4 DNA ligase to generate a 4-bp insertion.

RNA isolation, Northern blot analysis, and RNase protection assays were performed as described previously (Kim and Horvitz 1990; Miller et al. 1993). pML26 was derived from pML25 by SacI digestion and ligation with T4 DNA ligase. pML26 contains a 673-bp insert, extending from the SacI site in the mpk-1 sequence to the $5^{\prime}$ end of the cDNA clone. The first $78 \mathrm{bp}$ of this insert is from exon 1; the SLX2 RNA should hybridize to 595 nucleotides of this sequence because it lacks exon 1 . To make the probe that was used in the experiment shown in Figure 3B, pML26 was cut with XhoI and transcribed with T3 RNA polymerase, yielding a uniformly labeled RNA probe containing 673 nucleotides of insert sequence and 53 nucleotides of vector sequence. Scanning densitometry using a PhosphorImager (Molecular Dynamics) was used to quantitate the band intensities shown in Figure 3A.

\section{Acknowledgments}

We thank D. Waring for providing the cosmid that complements ncl-1, J. Kramer for providing pRF4, R. Barstead for pro- viding his cDNA library, A. Coulson and J. Sulston for placing mpk-1 on the physical map, P. Chuang for the $d p y-27$ and $y D f 10$ strains, and the C. elegans Genetic Center for providing strains. We thank E. Hafen, S.L. Zipursky, and M. Han for communicating results prior to publication. We thank D. Eisenmann, $R$. Hoskins, D. Kingsley, and J. Ferrell for comments on this manuscript. This work was supported by grants from the Lucille P. Markey Charitable Trust, the Searle Scholars Program/The Chicago Community Trust, National Institutes of Health and the Howard Hughes Medical Institute. K.K. was supported by a fellowship from the Damon Runyon-Walter Winchell Cancer Research Fund. L.M.M. was supported by an American Cancer Society postdoctoral fellowship. S.K.K. is a Lucille P. Markey scholar and a Searle scholar. H.R.H. is an Investigator of the Howard Hughes Medical Institute.

The publication costs of this article were defrayed in part by payment of page charges. This article must therefore be hereby marked "advertisement" in accordance with 18 USC section 1734 solely to indicate this fact.

\section{References}

Alvarez, E., I.C. Northwood, F.A. Gonzalez, D.A. Latour, A. Seth, C. Abate, T. Curran, and R.J. Davis. 1991. Pro-Leu-Ser/ Thr-Pro is a consensus primary sequence for substrate protein phosphorylation. Characterization of the phosphorylation of c-myc and c-jun proteins by an epidermal growth factor receptor threonine 669 protein kinase. I Biol Chem 266: 15277-15285.

Anderson, N.G., J.L. Maller, N.K. Tonks, and T.W. Sturgill. 1990. Requirement for integration of signals from two distinct phosphorylation pathways for activation of MAP kinase. Nature 343: 651-653.

Anderson, N.G., P. Li, L.A. Marsden, N. Williams, T.M. Roberts, and T.W. Sturgill. 1991. Raf-1 is a potential substrate for mitogen-activated protein kinase in vivo. Biochem. I. 277: 573-576.

Aroian, R.V. and P.W. Sternberg. 1991. Multiple functions of let-23, a Caenorhabditis elegans receptor tyrosine kinase gene required for vulval induction. Genetics 128: 251-267.

Aroian, R.V., M. Koga, J.E. Mendel, Y. Ohshima, and P.W. Sternberg. 1990. The let-23 gene necessary for Caenorhabditis elegans vulval induction encodes a tyrosine kinase of the EGF receptor subfamily. Nature 348: 693-699.

Barbacid, M. 1987. ras genes. In Annu. Rev. Biochem. 56: 779 827.

Barstead, R.J. and R.H. Waterston. 1989. The basal component of the nematode dense-body is vinculin. J. Biol. Chem. 264: 10177-10185.

Beitel, G.J., S.G. Clark, and H.R. Horvitz. 1990. Caenorhabditis elegans ras gene let-60 acts as a switch in the pathway of vulval induction. Nature 348: 503-509.

Biggs, W.H. III and S.L. Zipursky. 1992. Primary structure, expression, and signal-dependent tyrosine phosphorylation of a Drosophila homolog of extracellular-signal regulated kinase. Proc. Natl. Acad. Sci. 89: 6295-6299.

Blenis, J. 1993. Signal transduction via the MAP kinases: Proceed at your own RSK. Proc. Natl. Acad. Sci. 90: 5889-5892.

Boulton, T.G., G. Yancopoulos, J. Gregory, C. Slaughter, C. Moomaw, J. Hsu, and M.H. Cobb. 1990. An insulin-stimulated protein kinase similar to yeast kinases involved in cell cycle control. Science 249: 64-67.

Brenner, S. 1974. The genetics of Caenorhabditis elegans. Genetics 77: 71-94.

Chen, R.H., C. Sarnecki, and J. Blenis. 1992. Nuclear localiza- 
tion and regulation of erk- and rsk-encoded protein kinases. Mol. Cell. Biol. 12: 915-927.

Chou, S.-Y., V. Baichwal, and J.E.J. Ferrell. 1992. Inhibition of c-jun DNA binding by mitogen-activated protein kinase. Mol. Cell. Biol. 3: 1117-1130.

Clark, S.G., M.J. Stern, and H.R. Horvitz. 1992a. C. elegans cell-signalling gene sem-5 encodes a protein with $\mathrm{SH} 2$ and SH3 domains. Nature 356: 340-344.

Clark, S.G., M.J. Stern, and H.R. Horvitz. 1992b. Genes involved in two Caenorhabditis elegans cell-signaling pathways. In Cold Spring Harbor Symp. Quant. Biol. 57: 363-373. Cold Spring Harbor Laboratory Press, Cold Spring Harbor, New York.

Coulson, A., R. Waterston, J. Kiff, J. Sulston, and Y. Kohara. 1988. Genome linking with yeast artificial chromosomes. Nature 335: 184-186.

Crews, C.M., A. Alessandrini, and R.L. Erikson. 1992. The primary structure of MEK, a protein kinase that phosphorylates the ERK gene product. Science 258: 478-480.

Davis, R.J. 1993. The mitogen-activated protein kinase signal transduction pathway. J. Biol. Chem. 268: 14553-14556.

deVries-Smits, A.M., B.M. Burgering, S.J. Leevers, C.J. Marshall, and J.L. Bos. 1992. Involvement of p21ras in activation of extracellular signal-regulated kinase 2. Nature 357:602604.

Elion, E.A., P. Grisafi, and G.R. Fink. 1990. FUS3 Encodes a cdc2 + /CDC28-related kinase required for the transition from mitosis into conjugation. Cell 60: 649-664.

Ellis, H.M. and H.R. Horvitz. 1986. Genetic control of programmed cell death in the nematode C. elegans. Cell 44: $817-829$.

Ferguson, E.L. 1985. Genetic analysis of the pathway of vulval development in Caenorhabditis elegans. PhD Thesis, Massachusetts Institute of Technology, Cambridge, Massachusetts.

Ferguson, E.L. and H.R. Horvitz. 1985. Identification and characterization of 22 genes that affect the vulval cell lineages of the nematode Caenorhabditis elegans. Genetics 110: 17-72.

Ferguson, E.L., P.W. Sternberg, and H.R. Horvitz. 1987. A genetic pathway for the specification of the vulval cell lineages of Caenorhabditis elegans. Nature 326: 259-267.

Fire, A. 1986. Integrative transformation of Caenorhabditis elegans. EMBO I. 5: 2673-2681.

Frischauf, A.M., H. Lehrach, A. Poustka, and N. Murray. 1983. Lambda replacement vectors carrying polylinker sequences. J. Mol. Biol. 170: 827-842.

Gonzalez, F.A., A. Seth, D.L. Raden, D.S. Bowman, F.S. Fay, and R.J. Davis. 1993. Serum-induced translocation of mitogenactivated protein kinase to the cell surface ruffling membrane and the nucleus. J. Cell. Biol. 122: 1089-1101.

Greenwald, I.S. and H.R. Horvitz. 1980. unc-93(e1500): A behavioral mutant of Caenorhabditis elegans that defines a gene with a wild-type null phenotype. Genetics 96: 147-164.

Griswold-Prenner, I., C.R. Carlin, and M.R. Rosner. 1993. Mitogen-activated protein kinase regulates the epidermal growth factor receptor through activation of a tyrosine phosphatase. I. Biol. Chem. 268: 13050-13054.

Han, M. and P.W. Sternberg. 1990. let-60, a gene that specifies cell fates during $C$. elegans vulval induction, encodes a ras protein. Cell 63: 921-931.

Han, M., R.V. Aroian, and P.W. Sternberg. 1990. The let-60 locus controls the switch between vulval and nonvulval cell fates in Caenorhabditis elegans. Genetics 126: 899-913.

Han, M., A. Golden, Y. Han, and P.W. Sternberg. 1993. C. elegans lin-45 raf gene participates in let-60 ras-stimulated vulval differentiation. Nature 363: 133-139.
Hanks, S., A. Quinn, and T. Hunter. 1988. The protein kinase family: Conserved features and deduced phylogeny of the catalytic domains. Science 241: 42-52.

Herman, R.K. 1989. Mosaic analysis in the nematode Caenorhabditis elegans. I. Neurogenet. 5: 1-24.

Herman, R.K. and E.M. Hedgecock. 1990. Limitation of the size of the vulval primordium of Caenorhabditis elegans by lin15 expression in surrounding hypodermis. Nature 348: 169171.

Hill, R.J. and P.W. Sternberg. 1992. The gene lin-3 encodes an inductive signal for vulval development in $\mathrm{C}$. elegans. $\mathrm{Na}$ ture 358: 470-476.

Horvitz, H.R. and P.W. Stemberg. 1991. Multiple intercellular signalling systems control the development of the Cae. norhabditis elegans vulva. Nature 351: 535-541.

Horvitz, H.R. and J.E. Sulston. 1980. Isolation and genetic characterization of cell-lineage mutants of the nematode Caenorhabditis elegans. Genetics 96: 435-454.

Innis, M.A., D.H. Gelfans, J.J. Sninsky, and T.J. White. 1990 PCR protocols: A guide to methods and applications. Academic Press, San Diego, CA.

Kim, S.K. and H.R. Horvitz. 1990. The Caenorhabditis elegans gene $\operatorname{lin}-10$ is broadly expressed while required specifically for the determination of vulval cell fates. Genes \& Dev. 4: 357-371.

Kimble, J. 1981. Alterations in cell lineage following laser ablation of cells in the somatic gonad of Caenorhabditis elegans. Dev. Biol. 87: 286-300.

Koide, H., T. Satoh, M. Nakafuku, and Y. Kaziro. 1993. GTPdependent association of Raf-1 with Ha-Ras: Identification of Raf as a target downstream of Ras in mammalian cells. Proc. Natl. Acad. Sci. 90: 8683-8686.

Kramer, J.M., R.P. French, E.C. Park, and J.J. Johnson. 1990. The Caenorhabditis elegans rol-6 gene, which interacts with the sqt-1 collagen gene to determine organismal morphology, encodes a collagen. Mol. Cell. Biol. 10: 2081-2089.

Krause, M. and D. Hirsh. 1987. A trans-spliced leader sequence on actin mRNA in C. elegans. Cell 49: 753-761.

Kyriakis, J.M., H. App, X.F. Zhang, P. Banerjee, D.L. Brautigan, U.R. Rapp, and J. Avruch. 1992. Raf-1 activates MAP kinasekinase. Nature 358: 417-421.

Lambie, E.J. and J. Kimble. 1991. Genetic control of cell intereactions in nematode development. Ann. Rev. Genet. 25: 411-436.

Lee, R.M., M.H. Cobb, and P.J. Blackshear. 1992. Evidence that extracellular signal-regulated kinases are the insulin-activated Raf-1 kinase kinases. J. Biol. Chem. 267: 1088-1092.

Lenormand, P., C. Sardet, G. Pages, G. L'Allemain, A. Brunet, and J. Pouyssegur. 1993. Growth factors induce nuclear translocation of MAP kinases (p42mapk and p44mapk) but not of their activator MAP kinase kinase (p45mapkk) in fibroblasts. J. Cell. Biol. 122: 1079-1088.

Lowenstein, E.J., R.J. Daly, A.G. Batzer, W. Li, B. Margolis, R. Lammers, A. Ullrich, E.Y. Skolnik, S.D. Bar, and J. Schlessinger. 1992. The $\mathrm{SH} 2$ and $\mathrm{SH} 3$ domain-containing protein GRB2 links receptor tyrosine kinases to ras signaling. Cell 70: $431-442$.

Marais, R., J. Wynne, and R. Treisman. 1993. The SRF accessory protein Elk-1 contains a growth factor-regulated transcriptional activation domain. Cell 73: 381-393.

Matsuda, S., Y. Gotoh, and E. Nishida. 1993. Phosphorylation of Xenopus mitogen-activated protein (MAP) kinase kinase by MAP kinase kinase kinase and MAP kinase. J. Biol. Chem. 268: 3277-3281.

McCormick, F. 1993. Signal transduction. How receptors turn Ras on. Nature 363: 15-16. 
Mello, C.C., J.M. Kramer, D. Stinchcomb, and V. Ambros. 1991. Efficient gene transfer in C. elegans: Extrachromosomal maintenance and integration of transforming sequences. EMBO I. 10: 3959-3970.

Meneely, P.M. and R.K. Herman. 1979. Lethals, steriles and deficiencies in a region of the $\mathrm{X}$ chromosome of Caenorhabditis elegans. Genetics 92: 99-115.

Miller, L.M., M.E. Gallegos, B.A. Morrisseau, and S.K. Kim. 1993. lin-31, a Caenorhabditis elegans HNF-3/fork head transcription factor homolog, specifies three alternative cell fates in vulval development. Genes \& Dev. 7: 933-947.

Moodie, S.A., B.M. Willumsen, M.J. Weber, and A. Wolfman. 1993. Complexes of Ras.GTP with Raf- 1 and mitogen-activated protein kinase kinase. Science 260: 1658-1661.

Nakajima, T., S. Kinoshita, T. Sasagawa, K. Sasaki, M. Naruto, T. Kishimoto, and S. Akira. 1993. Phosphorylation at threonine- 235 by a ras-dependent mitogen-activated protein kinase cascade is essential for transcription factor NF-IL6. Proc. Natl. Acad. Sci. 90: 2207-2211.

Nishida, E. and Y. Gotoh. 1993. The MAP kinase cascade is essential for diverse signal transduction pathways. Trends Biochem. 18: 128-133.

Northwood, I.C., F.A. Gonzalez, M. Wartmann, D.L. Raden, and R.J. Davis. 1991. Isolation and characterization of two growth factor-stimulated protein kinases that phosphorylate the epidermal growth factor receptor at threonine 669. J. Biol. Chem. 266: 15266-15276.

Pages, G., P. Lenormand, G. L'allemain, J.-C. Chambard, S. Meloche, and J. Pouyssegur. 1993. Mitogen-activated protein kinases $\mathrm{p} 42^{\text {mapk }}$ and $\mathrm{p} 44^{\text {mapk }}$ are required for fibroblast proliferation. Proc. Natl. Acad. Sci. 90: 8319-8323.

Pelech, S.L. and J.S. Sanghera. 1992. MAP kinases: Charting the regulatory pathways. Science 257: 1355-1356.

Pulverer, B.J., J.M. Kyriakis, J. Avruch, E. Nikolakaki, and J.R. Woodgett. 1991. Phosphorylation of $\mathrm{c}$-jun mediated by MAP kinases. Nature 353: 670-674.

Sambrook, J., E.F. Fritsch, and T. Maniatis. 1989. Molecular cloning: A laboratory manual, 2nd ed. Cold Spring Harbor Laboratory Press, Cold Spring Harbor, New York.

Schaap, D., J. van der Wal, L.R. Howe, C.J. Marshall, and B.W. van. 1993. A dominant-negative mutant of raf blocks mitogen-activated protein kinase activation by growth factors and oncogenic p2lras. J. Biol. Chem. 268: 20232-20236.

Short, J.M., J.M. Fernandez, J.A. Sorge, and W.D. Huse. 1988. Lambda ZAP: A bacteriophage lambda expression vector with in vivo excision properties. Nucleic Acids Res. 16: 7583-7600.

Sternberg, P.W. 1988. Lateral inhibition during vulval induction in Caenorhabditis elegans. Nature 335: 551-554.

Sternberg, P.W. and H.R. Horvitz. 1986. Pattern formation during vulval development in C. elegans. Cell 44: 761-772.

Sulston, J.E. and H.R. Horvitz. 1977. Post-embryonic cell lineages of the nematode, Caenorhabditis elegans. Dev. Biol. 56: 110-156.

Sulston, J.E., E. Schierenberg, J.G. White, and J.N. Thomson. 1983. The embryonic cell lineage of the nematode Caenorhabditis elegans. Dev. Biol. 100: 64-119.

Takishima, K., P.I. Griswold, T. Ingebritsen, and M.R. Rosner. 1991. Epidermal growth factor (EGF) receptor T669 peptide kinase from 3T3-Ll cells is an EGF-stimulated "MAP" kinase. Proc. Natl. Acad. Sci. 88: 2520-2524.

Thomas, J.H., M.J. Stern, and H.R. Horvitz. 1990. Cell interactions coordinate the development of the C. elegans egg-laying system. Cell 62: 1041-1052.

Thomas, S.M., M. Demarco, G. D'arcangelo, S. Halegoua, and J.S. Brugge. 1992. Ras is essential for nerve growth factor- and phorbol ester-induced tyrosine phosphorylation of MAP kinases. Cell 68: 1031-1040.

Van, A.L., M. Barr, S. Marcus, A. Polverino, and M. Wigler. 1993. Complex formation between RAS and RAF and other protein kinases. Proc. Natl. Acad. Sci. 90: 6213-6217.

Vojtek, A.B., S.M. Hollenberg, and J.A. Cooper. 1993. Mammalian ras interacts directly with the serine/threonine kinase raf. Cell 74: 205-214.

Warne, P.H., P. Rodriguez-Viciana, and J. Downward. 1993. Direct interaction of Ras and the amino-terminal region of Raf-1 in vitro. Nature 364: 352-355.

Williams, B.D., B. Schrank, C. Huynh, R. Shownkeen, and R.H. Waterston. 1992. A genetic mapping system in Caenorhabditis elegans based on polymorphic sequence-tagged sites. Genetics 131: 609-624.

Wood, K.W., C. Sarnecki, T.M. Roberts, and J. Blenis. 1992. ras mediates nerve growth factor receptor modulation of three signal-transducing protein kinases: MAP kinase, Raf-1, and RSK. Cell 68: 1041-1050.

Wood, W.B., ed. 1988. The nematode Caenorhabditis elegans. Cold Spring Harbor Laboratory, Cold Spring Harbor, New York.

Young, R.A. and R.W. Davis. 1983. Yeast RNA polymerase II genes: isolation with antibody probes. Science 222: 778-782.

Zhang, X.F., J. Settleman, J.M. Kyriakis, S.E. Takeuchi, S.J. Elledge, M.S. Marshall, J.T. Bruder, U.R. Rapp, and J. Avruch. 1993. Normal and oncogenic p21ras proteins bind to the amino-terminal regulatory domain of c-Raf-1. Nature 364: 308-313. 


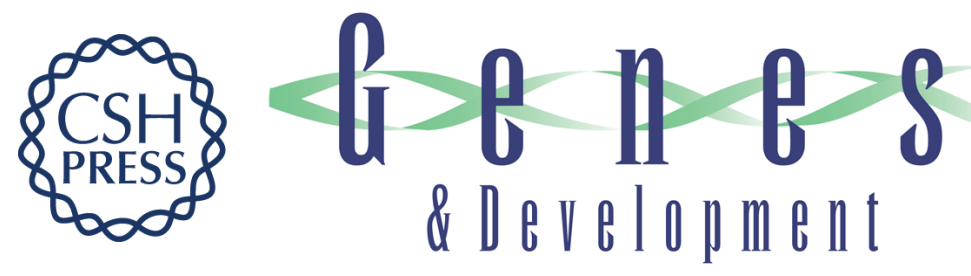

\section{A MAP kinase homolog, mpk-1, is involved in ras-mediated induction of vulval cell fates in Caenorhabditis elegans.}

M R Lackner, K Kornfeld, L M Miller, et al.

Genes Dev. 1994, 8:

Access the most recent version at doi:10.1101/gad.8.2.160

References This article cites 76 articles, 36 of which can be accessed free at:

http://genesdev.cshlp.org/content/8/2/160.full.html\#ref-list-1

License

Email Alerting

Service

Receive free email alerts when new articles cite this article - sign up in the box at the top right corner of the article or click here.

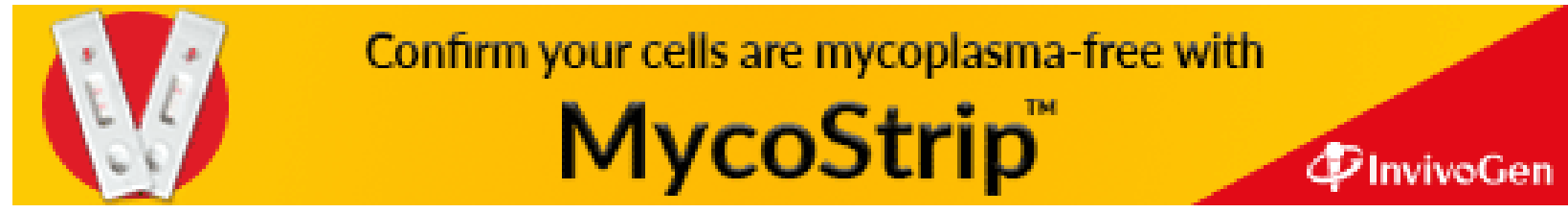

